\title{
Mental models and omissive causation
}

\author{
Sangeet Khemlani ${ }^{1} \cdot$ Christina Wasylyshyn $^{1} \cdot$ Gordon Briggs $^{1} \cdot$ Paul Bello $^{1}$
}

Published online: 19 July 2018

(C) This is a U.S. government work and its text is not subject to copyright protection in the United States; however, its text may be subject to foreign copyright protection 2018

\begin{abstract}
Some causal relations refer to causation by commission (e.g., "A gunshot causes death"), and others refer to causation by omission (e.g., "Not breathing causes death"). We describe a theory of the representation of omissive causation based on the assumption that people mentally simulate sets of possibilities - mental models - that represent causes, enabling conditions, and preventions (Goldvarg \& Johnson-Laird, 2001). The theory holds that omissive causes, enabling conditions, and preventions each refer to distinct sets of possibilities. For any such causal relation, reasoners typically simulate one initial possibility, but they are able to consider alternative possibilities through deliberation. These alternative possibilities allow them to deliberate over finer-grained distinctions when reasoning about causes and effects. Hence, reasoners should be able to distinguish between omissive causes and omissive enabling conditions. Four experiments corroborated the predictions of the theory. We describe them and contrast the results with the predictions of alternative accounts of causal representation and inference.
\end{abstract}

Keywords Omissions $\cdot$ Absences $\cdot$ Causal reasoning $\cdot$ Mental models $\cdot$ Negative possibilities $\cdot$ Double prevention

\section{Introduction}

A woman from Cincinnati was recently awarded $\$ 1.2$ million in a malpractice suit (Hunt, 2014). The jury found her doctor guilty because he had failed to give her a CT scan until she was critically ill and suffering from acute respiratory distress syndrome. According to the jury, by not diagnosing her illness in a timely manner, the doctor had caused permanent, debilitating damage to the woman.

When a doctor is a defendant in malpractice litigation concerning negligence, the central issue concerns omissive causation - that is, whether or not the absence of one or more actions adversely affected the patient. Omissive causation concerns a causal link between a failure of an event to occur and the consequences of that failure (see Paul \& Hall, 2013). Issues concerning causation by omission are prevalent in healthcare, public policy,

Electronic supplementary material The online version of this article (https://doi.org/10.3758/s13421-018-0841-5) contains supplementary material, which is available to authorized users.

Sangeet Khemlani

sunny.khemlani@nrl.navy.mil

1 Navy Center for Applied Research in Artificial Intelligence, Naval Research Laboratory, 4555 Overlook Ave SW, Washington, DC 20375, USA and in the legal profession (Ferrara, 2013), where the costs of a failure to act have monetary and legal consequences. But many theoretical frameworks for understanding causation have difficulty dealing with omissions. The problems are so severe that some philosophers suggest carving up causation into two distinct concepts to accommodate them (Hall, 2004; but cf. Strevens, 2013). As we will show, omissive causation is a challenge to cognitive psychologists as well, and few researchers have tackled the subject either experimentally or theoretically.

This article accordingly develops a new psychological theory of how humans represent causation by omission. We begin by reviewing the philosophical and psychological challenges that omissive causation presents. We then propose a novel account of omissive causation based on the construction of mental models. Mental models represent possible states of the world, observed or imagined (Goldvarg \& Johnson-Laird, 2001). This "model" theory relies on the assumption that people build discrete mental simulations to understand causal relations by commission (Johnson-Laird \& Khemlani, 2017; Khemlani, Barbey, \& Johnson-Laird, 2014), and we extend that analysis to omissions. We describe four experiments that test several diagnostic predictions of the proposed theory. Finally, we assess the theory in light of alternative accounts of causal cognition, and end with a discussion of outstanding issues and plans for future research that may further differentiate the model theory from other proposals. 


\section{Omissive causation in philosophy and psychology}

Philosophical treatments of omissive causation characterize the metaphysical properties of omissions - what they are and how they can be distinguished from commissive causationas well the situations to which omissive causal statements refer (Bernstein, 2014, 2016). They can be separated into two overarching families of theories: dependency theories and process theories. Dependency theories interpret causality with respect to statistical dependencies (Skyrms, 1980), counterfactual dependencies (Lewis, 1973), or structured probabilistic dependencies (Halpern \& Pearl, 2005) between events. For instance, under Lewis's account of counterfactual dependence, the following statement,

The doctor's failure to run the test caused the woman to suffer.

is true because the following counterfactual is true:

If the doctor had run the test, the woman would not have suffered.

In contrast, process theorists hold that causal relations refer to the transmission of some kind of quantity (Dowe, 1999; Salmon, 1984). Process theories often make specific claims about the vehicle or mode of causation, whereas many dependency theories do not. Omissive causation poses challenges for both types of theory. Causation by omission suggests the absence of a potential causal quantity; hence, process theorists have no quantity to transfer. Dependency theorists are vexed by the problem of "causal profligacy" (Menzies, 2004): many philosophical theories lack an appropriate mechanism to restrain causation from being applied liberally in cases of omission (e.g., Halpern \& Pearl, 2005; Lewis, 1973; Skyrms, 1980). In the case of medical malpractice, after all, the counterfactual above is true, but so are the following counterfactuals:

If another doctor had run the test, the woman would not have suffered.

If the doctor's grandmother had run the test, the woman would not have suffered.

If the doctor's dog had run the test, the woman would not have suffered.

Dependency theorists therefore have the burden of explaining how omissive causation applies to relevant agents in a particular scenario, rather than to the many other agents that might have otherwise impacted the outcome under discussion (McGrath, 2005). Following suggestions originally made by Hart and Honoré (1985), recent accounts propose that norms, typicality, and default assumptions determine the most intuitive cause of an outcome with multiple putative causes (e.g., Clarke, Shepherd, Stigall, Waller, \& Zarpentine, 2013; Hall, 2007; Halpern \& Hitchcock, 2014; Henne, Pinillos, \& De Brigard, 2017; Menzies, 2004, 2007).
Theorists continue to debate the metaphysics of omissive causation. Indeed, some have argued that the notion of causation is pluralistic such that the natural-language word "cause" masks a diverse set of relational concepts (Godfrey-Smith, 2009). A separate area of investigation addresses how human minds mentally represent, compose, and reason with omissive causal relations given limited cognitive bandwidth. These psychological issues motivate the remainder of our discussion.

Psychologists disagree about the mechanisms and representations that underlie causal reasoning in general (Sloman \& Lagnado, 2015). Like philosophers, some psychologists align with dependency theorists insofar as they focus on causal model structure (e.g., Goldvarg \& JohnsonLaird, 2001; Sloman, Barbey, \& Hotaling, 2009). Others mirror the process-theorists' arguments and appeal to the transmission of quantity to explain causal reasoning (e.g., Wolff, 2007; Wolff, Barbey, \& Hausknecht, 2010). A prominent feature of most extant psychological theories of causation is that they distinguish between the semantics and the representations of different causal relations, captured by causal verbs such as "causes," "enables," and "prevents." Thus far, however, no psychological account has sought to extend its semantic distinctions between causal relations to explain omissive causation. Indeed, the only existing robust psychological treatment of omissive causal representation and reasoning comes from Wolff and colleagues (Wolff et al., 2010). They argue more generally that humans treat causation as the transmission of a force (in line with process theorists), and that omissions are tantamount to the removal of a force. They do not, however, draw any distinction between different relations concerning omission such as omissive causation, omissive enabling conditions, and omissive prevention.

To address this discrepancy, we developed an account of omissive causation based on the construction and manipulation of mental models (Goldvarg \& Johnson-Laird, 2001). The theory shares an underlying assumption with theories based on mental simulations (e.g., Wolff et al., 2010): Reasoners build, compose, and inspect simulated causal relations when thinking about causal scenarios. But, unlike any previous account, it posits that reasoners represent such simulations by treating them as discrete possibilities (see Johnson-Laird, Khemlani, \& Goodwin, 2015) and not as collections of interacting forces. In the next section, we describe the general tenets of the theory and explain how it handles three different omissive causal relations.

\section{Mental models and omissive causation}

The mental model theory of reasoning - the "model" theory, for short - pertains to reasoning across many domains, including reasoning about temporal, spatial, causal, and abstract 
relations (Goldvarg \& Johnson-Laird, 2001; Goodwin \& Johnson-Laird, 2005), and reasoning based on sentential connectives, such as "if, "or," and "and" (Johnson-Laird \& Byrne, 1991; Khemlani, Byrne, \& Johnson-Laird, in press). The theory is built on three main principles (Johnson-Laird, 2006):

- People represent models - that is, sets of possibilitieswhen they reason: A given assertion refers to a conjunction of discrete possibilities that are observed or imagined (Khemlani et al., in press).

- The principle of iconicity: Mental models are iconic as much as possible, so that the model's structure preserves the structure of what it represents (see Peirce, 1958). But models can also include abstract symbols - for example, the symbol for negation (Khemlani, Orenes, \& JohnsonLaird, 2012).

- The principle of parsimony: Models require cognitive resources to construct and maintain, so mental models represent only what is possible and not what is impossible. Moreover, reasoners should make errors more frequently and take longer to draw conclusions when they need to keep multiple models in mind to solve a problem. As a result, reasoners should overlook possibilities inconsistent with a given statement.

The model theory distinguishes between mental models - models of an assertion that represent only those possibilities that render the assertion true-and fully explicit models - those that include additional possibilities that capture situations in which the premises are false. To illustrate these principles, we focus on the model theory's application to causal reasoning (Frosch \& Johnson-Laird, 2011; Goldvarg \& Johnson-Laird, 2001; Khemlani et al., 2014). The theory distinguishes between different causal relations - such as "cause," "enable," and "prevent"-by positing that those relations refer to different sets of possibilities - that is, distinct fully explicit models. Consider a causal assertion such as:

\section{Spraying a flower with acid causes it to die.}

The theory proposes that when reading Example 1, reasoners should construct simulations of three separate fully explicit models of possibilities, depicted in the following schematic diagram:

$$
\begin{array}{rr}
\text { acid } & \text { death } \\
\neg \text { acid } & \text { death } \\
\neg \text { acid } & \neg \text { death }
\end{array}
$$

The rows in the diagram represent different temporally ordered possibilities, and “ $\neg$ ” represents the symbol for negation
(Khemlani et al., 2012). Hence, the first row represents the situation in which a flower is sprayed with acid and then dies, the second row represents a situation in which a flower is not sprayed with acid and dies anyway (for some other reason), and the third row represents a situation in which a flower is not sprayed with acid and lives. The assertion in Example 1 rules out those situations in which the flower is sprayed with acid and does not die. Indeed, when asked to list what is possible given the assertion in Example 1, reasoners tend to list those three possibilities (Goldvarg \& Johnson-Laird, 2001, Exp. 2). However, the theory predicts that for more complex reasoning tasks, maintaining all three models in memory should be difficult, so it posits that reasoners tend to maintain only mental models that are a proper subset of the fully explicit models. The mental model of the assertion concerns only the first possibility:

acid death

Reasoners can flesh out the other possibilities, but they do so only when prompted to, so they err systematically as a result of representing only mental models and not fully explicit models (for corroboratory evidence, see Goldvarg \& Johnson-Laird, 2001, Exp. 4).

Mill (1874) rejected any distinction between causal relations and enabling conditions, and many contemporary theorists maintain that enabling conditions are a form of causation (e.g., Hart \& Honoré, 1985). Some have proposed that causes violate norms by default, whereas enabling conditions do not (see e.g., Einhorn \& Hogarth, 1986; Kahneman \& Miller, 1986). Cheng and Novick (1991) argued that causes are inconstant, whereas enabling conditions are constant given a relevant situation. Yet others have proposed that causes are relevant and highlighted by speakers, whereas enablers are often not the topic of discourse (e.g., Hilton \& Erb, 1996). But humans appear to distinguish between causation and enabling conditions when all of these factors are controlled (Frosch \& Johnson-Laird, 2011). Consider the enabling assertion in Example 2:

\section{Exposing a flower to light enables it to bloom.}

The model theory posits that Example 2 refers to the following possibilities:

$$
\begin{array}{rr}
\text { light } & \text { bloom } \\
\text { light } & \neg \text { bloom } \\
\neg \text { light } & \neg \text { bloom }
\end{array}
$$

The second possibility in the set above allows that the flower may not bloom in the presence of light. Hence, in general, the models of enabling conditions are different from those of causal relations. The causal relation in (1) prohibits the 
possibility in which the first clause holds and the second clause doesn't (i.e., acid is sprayed and the flower does not die), but the enabling relation in Example 2 permits the possibility (i.e., flower is exposed to light and it does not bloom).

The differences in interpretation are often masked, however, because just as with causal assertions, reasoners do not tend to build fully explicit models of enabling conditions. Instead, they consider only the first possibility:

light bloom

Hence, the mental models of causes and enabling conditions are identical - for example, the mental models of "Event A causes event B" and "Event A enables event B" are both

\section{Event-A Event-B}

For that reason, the model theory predicts that individuals should often conflate enabling with causing relations, but that they can systematically distinguish between the two when prompted. Evidence corroborates the conflation (Goldvarg \& Johnson-Laird, 2001, Exp. 5).

Prevention in the model theory-for instance, "acid prevents a flower from blooming"-is interpreted in a manner equivalent to "acid causes the flower not to bloom." Hence, models are built by tagging antecedent events with symbols for negation,

$$
\begin{array}{rr}
\text { acid } & \neg \text { bloom } \\
\neg \text { acid } & \neg \text { bloom } \\
\neg \text { acid } & \text { bloom }
\end{array}
$$

and the mental model of a prevention is accordingly

$$
\text { acid } \neg \text { bloom }
$$

The model theory therefore treats prevention as a cause of a negated event.

Background knowledge and pragmatics can block the construction of certain possibilities when reasoning about causal relations (Johnson-Laird \& Byrne, 2002). For instance, the statement "consuming alcohol causes drunkenness" is inconsistent with the situation in which drunkenness occurs in the absence of alcohol. Thus, instead of these models,

$$
\begin{array}{rr}
\text { alcohol } & \neg \text { drunkenness } \\
\neg \text { alcohol } & \neg \text { drunkenness } \\
\neg \text { alcohol } & \text { drunkenness }
\end{array}
$$

reasoners should consider only the first two

$$
\begin{aligned}
\text { alcohol } & \neg \text { drunkenness } \\
\neg \text { alcohol } & \neg \text { drunkenness }
\end{aligned}
$$

which constitute a stronger notion of causation than the one that reasoners think of in the absence of background knowledge. The assertion is akin to a biconditional: "If and only if alcohol is consumed, drunkenness will occur". Such considerations apply to enabling and prevention conditions as well, and Table 1 shows both strong and weak interpretations of causal relations. Altogether, the theory posits that reasoners should distinguish between the six sets of possibilities depicted in the table.

Given the distinctions in meaning between causal relations, how might the model theory account incorporate causation by omission? We describe an account in the next section.

\section{Negative events and models of causation}

We extend the model theory of causal reasoning with the following assumption:

The principle of omissions: Reasoners interpret omissions (absences, lacks, and failures) by negating antecedent events. They represent negated events as models tagged with symbols for negation.

Negative events are controversial concepts among philosophers, because whereas positive events occur in a specific spatiotemporal frame, negative events do not (Paul \& Hall, 2013, p. 178). But reasoners have little difficulty comprehending negative events; they routinely do so when reasoning about counterfactuals - that is, situations that could have happened but did not (Byrne, 2005). So, negative events are viable psychological constructs, because they can be interpreted and mentally represented. Evidence suggests that reasoners interpret negations by integrating abstract symbols for negation into mental simulations (see Khemlani et al., 2014; Khemlani et al., 2012; Orenes, Beltrán, \& Santamaría, 2014). They may be detected as a result of a violation of an affirmed expectation, or they may be interpreted by explicitly negating an antecedent by using such phrases as "not," "the absence of," "the failure of," and "the lack of," as in "The lack of X causes Y."

The principle we posit minimally adapts the semantics of the model theory to distinguish between cases of omissive causation, omissive enabling, and omissive prevention, as well as their strong and weak interpretations. Consider the following assertion:

3. Not providing a flower with light causes it to die.

The assertion is similar to its commissive causal counterpart above in Example 1, except that it concerns a negative antecedent possibility, so its mental model is as follows:

$\neg$ light death 
Table 1 Core meanings of causal relations, enabling conditions, and preventions in terms of the conjunctions of the temporally ordered possibilities to which they refer

The Possibilities Yielding Distinct Causal Relations

\begin{tabular}{|c|c|c|c|c|c|}
\hline A $B$ & A $B$ & A $\mathrm{B}$ & A $B$ & $\mathrm{~A} \neg \mathrm{B}$ & $\mathrm{A} \neg \mathrm{B}$ \\
\hline$\neg \mathrm{A} \neg \mathrm{B}$ & $\neg \mathrm{A} \neg \mathrm{B}$ & $\mathrm{A} \neg \mathrm{B}$ & $\mathrm{A} \neg \mathrm{B}$ & $\neg \mathrm{A} \neg \mathrm{B}$ & $\neg \mathrm{A} \quad \mathrm{B}$ \\
\hline$\neg \mathrm{A} \quad \mathrm{B}$ & & $\begin{array}{l}\neg \mathrm{A} \neg \mathrm{B} \\
\neg \mathrm{A} \quad \mathrm{B}\end{array}$ & $\neg \mathrm{A} \neg \mathrm{B}$ & $\neg \mathrm{A} \quad \mathrm{B}$ & \\
\hline
\end{tabular}

Commissive causation

A causes B

Weak

Strong

A enables B

Weak

Strong

A prevents $B$

The Possibilities Yielding Distinct Omissive Causal Relations

\begin{tabular}{|c|c|c|c|c|c|}
\hline$\neg \mathrm{A} \quad \mathrm{B}$ & $\neg \mathrm{A} \quad \mathrm{B}$ & $\neg \mathrm{A} \quad \mathrm{B}$ & $\neg \mathrm{A} \quad \mathrm{B}$ & $\neg \mathrm{A} \neg \mathrm{B}$ & $\neg \mathrm{A} \neg \mathrm{B}$ \\
\hline $\mathrm{A} \neg \mathrm{B}$ & $\mathrm{A} \neg \mathrm{B}$ & $\neg \mathrm{A} \neg \mathrm{B}$ & $\neg \mathrm{A} \neg \mathrm{B}$ & $\neg \mathrm{A} \neg \mathrm{B}$ & A \\
\hline A B & & $\begin{array}{l}\mathrm{A} \neg \mathrm{B} \\
\mathrm{A} \quad \mathrm{B}\end{array}$ & $\mathrm{A} \neg \mathrm{B}$ & A $B$ & \\
\hline
\end{tabular}

Omissive causation

Not doing A causes B

Weak

Strong

Not doing A enables B

Weak

Strong

Not doing A prevents B

Strong interpretations correspond to unique causes, enablers, and preventers; weak interpretations allow for other antecedent events. The core meanings of omissive causal relations, omissive enabling conditions, and omissive preventions merely reverse the polarity of the antecedent event - that is, A becomes $\neg \mathrm{A}$, and vice versa.

The mental model can be fleshed out into its fully explicit models:

$$
\begin{array}{rr}
\neg \text { light } & \text { death } \\
\text { light } & \text { death } \\
\text { light } & \neg \text { death }
\end{array}
$$

The assertion accordingly refers to three situations: one in which the flower gets no light and dies, one in which the flower gets light and dies, and one in which the flower gets light and does not die. A strong omissive enabling condition, such as:

\section{Not plucking a flower enables it to bloom.}

refers to the same mental model as that of omissive causation-that is:

$\neg$ pluck bloom

But its fully explicit models refer to an expanded set of possibilities:

$$
\begin{array}{rr}
\neg \text { pluck } & \text { bloom } \\
\neg \text { pluck } & \neg \text { bloom } \\
\text { pluck } & \neg \text { bloom }
\end{array}
$$

For strong enabling conditions, the only possibility that renders the statement false is one in which a flower is plucked and then blooms anyway (see Table 1). For weak enabling conditions - for example,

5. Not spraying a flower with acid enables it to bloom.

the fully explicit models permit all contingent possibilities:

$$
\begin{array}{rr}
\neg \text { acid } & \text { bloom } \\
\neg \text { acid } & \neg \text { bloom } \\
\text { acid } & \text { bloom } \\
\text { acid } & \neg \text { bloom }
\end{array}
$$

The relation in Example 5 is weaker than the one in Example 4, because it's possible that a flower can recover from a spray of acid and bloom anyway.

Just as in the case of commissive causation, the mental models reveal that omissive causes are often conflated with omissive enabling conditions, because the mental models of "Not doing A causes B" and "Not doing A enables B" are identical, namely:

$$
\neg \mathrm{A} \quad \mathrm{B}
$$

The model theory posits that reasoners who conflate causal relations with enabling conditions do so erroneously, as a 
result of failing to take into account all the possibilities to which the relations refer.

Finally, an omissive prevention holds for assertions such as:

6. The absence of light prevents a flower from blooming.

Its mental models are

$\neg$ light $\neg$ bloom

and its fully explicit models are

$\neg$ light $\neg$ bloom

light $\neg$ bloom

light bloom

Background knowledge can block some of the possibilities in omissive preventions, as well; see Table 1.

The theory accordingly distinguishes between omissive causation, omissive enabling conditions, and omissive prevention. Like other theories of causal reasoning (e.g., Wolff, 2007), it predicts that reasoners often conflate causes and enabling conditions. But it makes three novel predictions, as well:

- Prediction 1: Reasoners should privilege the possibilities that correspond to mental models over other possibilities: They should construct and evaluate the former possibilities first and most often (i.e., not-A and $B$ for omissive causes and omissive enabling conditions).

- Prediction 2: Reasoners should discriminate between omissive causation and omissive enabling conditions on the basis of the contingencies that differ between them. For instance, not- $A$ and not- $B$ is consistent with omissive enabling conditions but not with an omissive causal relation (strong or weak).

- Prediction 3: Reasoners should infer a strong omissive enabling condition on the basis of an incompatibility with the $A$ and $B$ possibility; also, they should infer a weak omissive prevention condition based on a compatibility with not-A and not-B and its incompatibility with not-A and $B$.

A pilot experiment revealed that participants appear to distinguish omissive causes and omissive enabling conditions when assessing whether contingencies are possible or impossible (see the supplementary materials). In four experiments, we tested the theory's predictions directly. In Experiments 1 and 2, participants assessed whether the four contingencies were possible, given statements that asserted omissive causes and omissive enabling conditions. In Experiment 3, participants assessed the consistency of two assertions: an omissive relation-for example,
"The absence of A will cause B" - and one of the four contingencies-for example, "A does not occur and B occurs." In Experiment 4, participants viewed animations that corresponded to one of three omissive relations (an omissive cause, an omissive enabling condition, and an omissive prevention), and they were asked to select a sentence that most appropriately described the set of animations. These experiments corroborated the model theory's predictions.

\section{Experiment 1}

Experiment 1 tested the first and second predictions of the model theory directly: Reasoners should privilege mental models, and they should distinguish omissive causal relations from omissive enabling conditions. To assess the predictions, participants read a short vignette about fictitious scenarios that concerned a magical spell (e.g., "dalgant") and its relation to fictitious ailments (e.g., "kandersa disease"). A typical sentence describing the relation was as follows:

Not casting dalgant will cause Doris to have kandersa disease.

Fictitious materials were used in order to eliminate the potential for participants' background knowledge to bias the way they interpreted causal relations. Likewise, the use of individual victims (e.g., "Doris") was designed to encourage participants to think about the specific scenario presented instead of how diseases work in general. The vignettes asserted either an omissive causal relation of the form "Not casting A causes B," or else an omissive enabling condition, "Not casting A enables B." Participants then assessed which of the four contingencies were possible, given the assertion.

\section{Method}

Participants A preregistered power analysis on pilot data suggested an ideal participant pool of 50 participants (power = .95), so 54 participants were recruited through Amazon Mechanical Turk. In the subsequent experiments in this article, we used fewer participants, but post-hoc power analyses revealed that all the experiments yielded a power of $>.70$. All participants in Experiment 1 completed the experiment for monetary compensation and were US native English speakers. A postexperimental questionnaire assessed whether the participants had backgrounds in formal logic; 35 participants reported no formal training in logic, and the rest reported introductory to advanced training.

Open science The predicted effects and analyses were preregistered via the Open Science Framework. The 
preregistration information, experimental code, materials, design, and analysis scripts for Experiment 1 and all subsequent experiments are provided at https://osf.io/6dyjh/.

Procedure Participants carried out the experiment on a computer screen over the Internet. The experiment was implemented in psiTurk (Gureckis et al., 2016), as were all subsequent experiments. Participants read a set of instructions and completed two example problems before completing eight experimental problems. The problems consisted of a single statement that asserted an omissive causal relation. An example problem is as follows:

Suppose the following statement is true:

Not casting dalgant will cause Doris to have kandersa disease.

Select each situation that is possible given the scenario.

Dalgant is cast and Doris has kandersa diseases.

(A and $\mathrm{B})$

Dalgant is cast and Doris does not have kandersa disease.

(A and not-B)

Dalgant is not cast and Doris has

kandersa disease.

(Not-A and B)

Dalgant is not cast and Doris does not have kandersa disease.

(Not-A and not-B)

Participants' responses were coded for four dependent variables: whether or not they selected $A$ and $B$, whether or not they selected $A$ and not- $B$, and so on for the other two options. The information for each problem was presented simultaneously, and participants were not allowed to continue to the next problem until they had selected at least one possibility.

Design and materials Participants acted as their own controls and received eight problems. Half of the problems concerned omissive causation, and half concerned omissive enabling conditions. The order of the problems and the presentation order of the four contingencies were randomized. The contents of the problems (i.e., the names of the spells, the victims, and the diseases) were randomly assigned, and the randomization made it improbable that any two participants would receive the exact same combination of materials. The phrasing used to establish an omissive relationship made use of explicit negation, as in, "Not casting X. ..."

\section{Results and discussion}

Figure 1 presents the proportions of selections of the four logical contingencies as a function of the causal relation in the problems. To test the theory's predictions directly, nonparametric planned comparisons were conducted. Participants privileged the contingencies that corresponded to the mental model: They selected not-A and B on $89 \%$ of the problems but $A$ and not- $B$ on $58 \%$ of the problems (Wilcoxon test, $z=5.78, p<.0001$, Cliff's $\delta=.39$ ). Hence, the data validated the theory's first prediction. Planned comparisons did not detect a difference in participants' tendency to select not-A and $B$ as a function of the causal relation described in the vignette - that is, "will cause" versus "will enable" (Wilcoxon test, $z=1.22, p=.22$, Cliff's $\delta=$ .06). An analogous comparison detected no reliable difference for $A$ and not- $B$ (Wilcoxon test, $z=1.10, p=.27$, Cliff's $\delta=$ $.02)$. These results corroborated the theory's second prediction. Participants' tendencies to select $A$ and $B$ and not- $A$ and not- $B$ likewise corroborated the theory's second prediction: They judged $A$ and $B$ to be possible reliably more often for "will cause" than for "will enable" (18\% vs. 9\%; Wilcoxon test, $z=2.31, p=.02$, Cliff's $\delta=0.15$ ), and they judged not-A and not- $B$ to be possible more often for enabling conditions ( $18 \%$ ) than for causes ( $7 \%$; Wilcoxon test, $z=2.00$, $p=.046$, Cliff's $\delta=.11$ ). The results yielded the interaction predicted by the model theory: Participants selected not- $A$ and not- $B$ more often than $A$ and $B$ for enabling conditions, but the pattern reversed for causes (Wilcoxon test, $z=2.42, p=.02$, Cliff's $\delta=0.28$ ).

Experiment 1 corroborated the key predictions of the model theory: Participants privileged possibilities that described mental models more than any other option (Prediction 1). Likewise, their tendency to accept $A$ and $B$, as well as their tendency to accept not-A and not- $B$, differed depending on the causal verb ("will cause" vs. "will enable") that was described (Prediction 2). Hence, the experiment demonstrated that people distinguish omissive causal relations from omissive enabling conditions.

Nevertheless, participants' tendencies to select $A$ and $B$ as well as not-A and not- $B$ possibilities were low overall. As Fig. 1 shows, participants selected not- $A$ and $B$ and $A$ and not- $B$ as possible the vast majority of the time, which suggests that they considered the other two scenarios impossible. One reason for this behavior may have been because of our use of fictitious

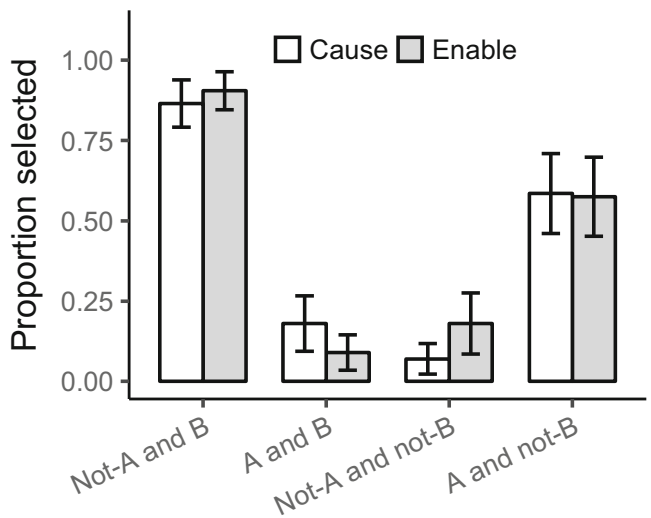

Fig. 1 Proportions of responses selected for the four contingencies in Experiment 1 as a function of the causal relation (cause vs. enable). Error bars show $95 \%$ confidence intervals 
materials - that is, "blank predicates." Because the materials were unfamiliar to participants, they may have encouraged more conservative interpretations - for instance, participants may have interpreted a causal relation as a strong causal relation that concerned only two possibilities. Experiment 2 sought to correct this limitation by using materials that described common relations for which participants likely had considerable background knowledge.

\section{Experiment 2}

Experiment 2 was similar to Experiment 1, except that it used sensible materials that described plausible situations in real life. Also, the experiment was conducted in a laboratory setting, with the experimenter present, instead of over the Internet.

\section{Method}

Participants A total of 20 volunteers from the Naval Research Laboratory participated in the experiment (nine females and 11 males; mean age $=40.1$ years). A postexperimental questionnaire assessed whether participants had backgrounds in formal logic; eight participants reported no formal training in logic, and the rest reported introductory to advanced training. All participants were native English speakers.

Procedure Participants followed the same procedure described in Experiment 1 and completed the experiment through a Web browser. After reading a set of instructions, they completed two example problems and 14 experimental problems. The problems consisted of two premises: The first premise introduced a context and some entity relevant to the context, and the second asserted a causal relation relevant to the entity. An example problem is as follows:

\section{Suppose the following statements are true:}

1. A particular car engine requires maintenance.

2. The lack of a particular part will [cause / enable] the engine to fail.

Select each situation that is possible given the scenario.

The car has the part and the engine fails. (A and B)

The car has the part and the engine doesn't fail.

The car doesn't have the part and the engine fails.

(A and not-B)

The car doesn't have the part and the engine doesn't fail.

(Not-A and B)

(Not-A and not-B)

In the example problem, the first premise establishes a context relevant to a car engine, and the second premise refers to a causal relation relevant to how car engines operate.
Participants' responses were coded as in Experiment 1. As in the previous experiment, the information for each problem was presented simultaneously, and participants were not allowed to continue to the next problem until they had selected at least one possibility. But, unlike in the previous experiment, the experimenter was present during the course of Experiment 2, and participants could ask questions for clarification.

Design and materials Participants acted as their own controls and received 14 problems. Half of the problems concerned omissive causation, and half concerned omissive enabling conditions. The order of the problems and the presentation order of the four contingencies were randomized. The contents of the problems were randomly assigned from a set of materials that concerned scenarios from four domains: biolog$\mathrm{ical} / \mathrm{physiological}$, natural, social/economical, and mechanical (see the Appx.). The phrasing used to establish an omissive relationship was held constant for each material, and it occurred in one of three ways: "lack of," "absence of," or explicit negation (e.g., not doing A).

\section{Results and discussion}

Figure 2 presents the proportions of selections of the four logical contingencies as a function of the causal relation in the problems. As in the previous experiment, nonparametric planned comparisons were conducted. The data corroborated the first prediction of the model theory, that participants would privilege contingencies that corresponded to the mental model: They selected not-A and $B$ on $98 \%$ of the problems, and $A$ and not- $B$ on $89 \%$ of the problems (Wilcoxon test, $z=3.00, p=.002$, Cliff's $\delta=.18$ ). In line with the second prediction of the model theory, the tendency to select not- $A$ and $B$ did not differ as a function of whether the relevant causal relation was a cause or an enabling condition, and likewise for $A$ and not- $B$ (Wilcoxon tests, $z \mathrm{~s}<1.0, p \mathrm{~s}>.32$, Cliff's $\delta<.05)$. Their tendency to

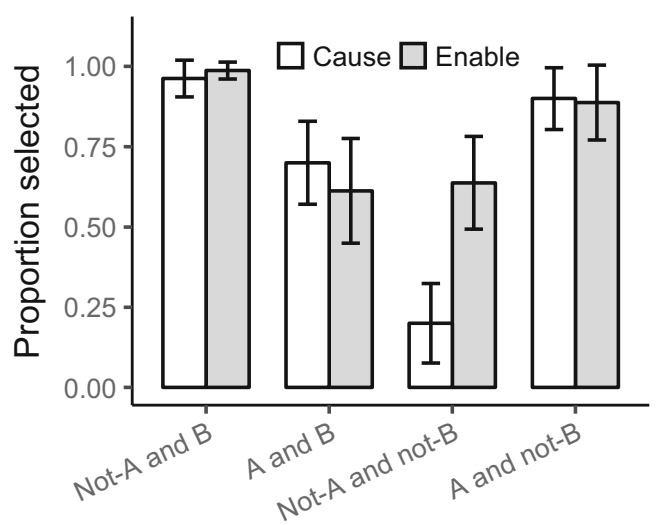

Fig. 2 Proportions of responses selected for the four contingencies in Experiment 2 as a function of the causal relation (cause vs. enable). Error bars show $95 \%$ confidence intervals 
select $A$ and $B$ also corroborated the theory's second prediction: More participants accepted $A$ and $B$ as possible when it was presented with a cause than when it was presented with an enabling condition, but the difference was not reliable ( $70 \%$ vs. $61 \%$; Wilcoxon test, $z=1.26, p=.21$, Cliff's $\delta=0.13$ ), a result that contravened the second prediction of the theory. However, participants selected not-A and not- $B$ much more often for enabling conditions $(64 \%)$ than for causes (20\%; Wilcoxon test, $z=3.24, p=.001$, Cliff's $\delta=.70$ ), which corroborated the second prediction. Hence, the results yielded an interaction uniquely predicted by the theory: Participants selected not-A and not- $B$ more often than $A$ and $B$ for enabling conditions, but the pattern reversed for causes (Wilcoxon test, $z=3.18, p=.001$, Cliff's $\delta=0.65$ ).

The results of Experiment 2 corroborated the predictions of the model theory. Most importantly, participants distinguished between omissive causes and omissive enabling conditions; that is, they evaluated not-A and not-B as possible for omissive enabling conditions but not for omissive causal relations. The experiment also showed that reasoners selected $A$ and $B$ more often for causal relations than for enabling conditions, but the difference was unreliable. This might have reflected weak interpretations of enabling conditions (see Table 1). Nevertheless, the predicted interaction between the evaluation of the two contingencies as a function of causal versus enabling relations was significant. The participants in Experiment 2 judged $A$ and $B$ and not- $A$ and not- $B$ to be possible far more often than did those in Experiment 1, which indeed suggests that the participants in Experiment 1 made conservative interpretations.

Experiments 1 and 2 concerned evaluations of possibility. The task was limited in that it provided participants with multiple options to evaluate. Participants were permitted to select and unselect options as they pleased until they were satisfied, and those deliberations may have biased their responses. The counterbalancing procedure used in Experiment 2 was limited, as well: Materials were drawn at random for each participant from the pool of materials (see the Appx.), so the materials were not presented in a uniformly counterbalanced manner. Experiment 3 corrected for both issues.

\section{Experiment 3}

Experiment 3 tested the first two predictions of the model theory using a task designed to elicit judgments of consistency. Each problem consisted of a premise that stipulated a causal relationship (e.g., "A will cause B" or "A will enable B") and a premise that asserted one contingency of the four that were possible. Participants judged whether both assertions could be true at the same time. The experiment was conducted online in order to draw from a diverse pool of participants.

\section{Method}

Participants In all, 30 participants (18 female, 11 male, and one whose gender was not specified; mean age $=38.3$ years) volunteered through the Amazon Mechanical Turk online platform (see Paolacci, Chandler, \& Ipeirotis, 2010, for a review). Eighteen of the participants reported no formal logic or advanced mathematical training, and the remainder reported introductory to advanced training in logic. All participants were native English speakers.

Procedure Participants completed two practice problems and 16 experimental problems. Each problem consisted of three premises: The first established a context, the second asserted a causal relation or else an enabling condition between two relevant entities, and the third presented a conjunction representing one of the four possible contingencies. Participants judged whether the latter two premises could be true at the same time, which was equivalent to asking whether the two statements were consistent with one another. Here is an example problem:

\section{A forest is on fire. Consider the following two statements: \\ 1. The lack of wind will [causelenable] the fire to dissipate. \\ 2. There is wind and the fire doesn't dissipate. Can both (1) and (2) be true at the same time?}

Participants indicated their response by pressing a button for "yes" or for "no" for each scenario before proceeding to the next trial. All information for each trial was presented simultaneously, and participants were permitted to take as long as they needed to read the scenarios and make their responses.

Design Participants acted as their own controls, and each participant was presented with all 16 problems. The experiment varied the conjunction in the second premise - that is, it occurred as $A$ and $B$, not- $A$ and $B, A$ and not- $B$, or not- $A$ and not$B$. Hence, participants received each of the four conjunctions four times, yielding 16 presentations in total. Within these groups, half of the problems concerned causes, and the other half concerned enabling conditions. The 16 materials in the experiment (provided in the Appx.) were rotated over the problems following a Williams square design (see Williams, 1949), which was used to control for carryover effects between the evaluations. Each material was therefore distributed uniformly over the eight conditions in the experiment.

Materials The 16 materials used in the previous experiment were used once again in Experiment 3 (see the Appendix). The materials represented four domains: mechanical, biological/physiological, natural, and social/economical. As in the previous experiment, the omissive relationship in each problem was established by using one of three phrases: "lack of," "absence of," or an explicit negation (e.g., not doing A). 


\section{Results and discussion}

Figure 3 presents the proportions of selections of the four logical contingencies as a function of causal relation when participants were asked to evaluate the consistency of two statements. Nonparametric planned comparisons tested the theory's predictions directly.

As in the previous experiment, participants selected not- $A$ and $B$ reliably more often than $A$ and not- $B(97 \%$ vs. $86 \%$, Wilcoxon test, $z=2.70, p=.006$, Cliff's $\delta=0.17$ ), and hence they privileged the contingency that corresponded to a mental model over the one that didn't. This result corroborated the first prediction of the theory. Their judgments of consistency did not differ reliably for $A$ and $B$ depending on the causal relation in the premises (Wilcoxon test, $z=0.92, p=.36$, Cliff's $\delta=0.03$ ). But participants did judge not-A and not-B to be consistent with enabling conditions (43\%) more often than they judged it to be consistent with causal relations (17\%; Wilcoxon test, $z=3.08, p=.002$, Cliff's $\delta=0.34$ ). Hence, the interaction consistent with the model theory's second prediction was reliable: Participants chose not-A and not-B more for enabling conditions than for causes, whereas their judgments of $A$ and $B$ did not differ (Wilcoxon test, $z=4.06, p<.0001$, Cliff's $\delta=0.27$ ).

Because Experiment 3 presented materials uniformly to participants, and because its design eliminated the possibility that the results were due to carryover effects, it was possible to test whether the interaction came about for some materials more than others. We accordingly subjected the data to a generalized logistical mixed-effects analysis (see, e.g., Barr, Levy, Scheepers, \& Tily, 2013; Bates, Kliegl, Vasishth, \& Baayen, 2015). The model controlled for random effects due to participant variability, material variability, and training in logic. The regression corroborated the nonparametric analyses; that is, it revealed a significant interaction between the tendency to assess a contingency to be consistent as a function of the contingency itself (not-A and

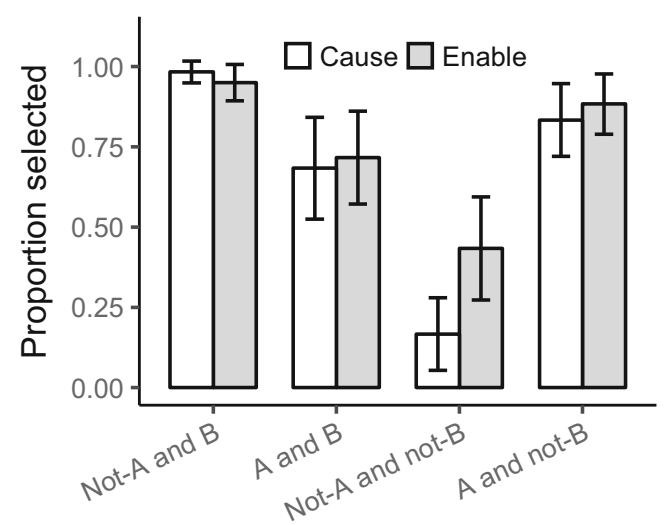

Fig. 3 Proportions of responses selected for the four contingencies in Experiment 3 as a function of the causal relation (cause vs. enable). Error bars show $95 \%$ confidence intervals not- $B$ vs. $A$ and $B)$ and as a function of the causal relation $(B=0.86, z=2.38, p=.02)$.

The theory predicted that participants should judge the $A$ and $B$ contingency to be consistent with enabling conditions but inconsistent with causes, but participants did not exhibit such a pattern in Experiment 3. One reason for the aberrant result may have been the particular task used in Experiment 3. Assessments of consistency are similar to assessments of possibility, except that untutored reasoners tend to have difficulty understanding what is meant by a "judgment of consistency." So, in lieu of technical jargon, Experiment 3 adopted more transparent language; that is, the experiment called for participants to answer the question "Can both (1) and (2) be true at the same time?" The question made use of the modal auxiliary verb "can," which is often used to indicate capability, as in "He can rob the bank, but he won't." Its usage might have encouraged participants to weaken their default interpretations of the enabling conditions: By default, reasoners tend to construe enabling conditions as being strong, as in "placing bullets in the chamber enables a gun to fire." But the causal verb "enables" can have a weaker construal as well, as in "studying hard enables a student to get into college." The former usage of "enables" prohibits the situation in which the gun fires without bullets in the chamber, but the latter usage makes no such prohibition, since the statement is true even though students can get into college without studying hard (such as if they happen to be wealthy or athletic; see Table 1). The pattern in this experiment was unexpected and perhaps an artifact of the verbal nature of the task. To overcome the task's limitation and assess the third prediction of the model theory, Experiment 4 presented participants with a visual domain in which they observed diverging possibilities from animations instead of comprehending them from assertions.

\section{Experiment 4}

Experiment 4 tested the second and third predictions of the model theory in a visual domain, using an animation-sentence verification task designed to elicit participants' evaluations of causal relationships from observed possibilities. The animations concerned the physical interactions of a ball moving toward a goal through a tube. A gate that could cover the tube served to block the ball from reaching the goal, to redirect it, or to have no interaction with the ball whatsoever (i.e., when the gate was left open). The tube through which the ball could enter was forked into two separate outlets, and in many animations the goal was placed at the end of only one of the outlets. In that way, whenever the ball entered the tube, it could result in either a goal or a failure to reach the goal. The forked tube therefore allowed for the construction of a 
wide range of materials useful for diagnosing the predictions of the model theory (see Table 2).

Participants viewed three animations that corresponded to the various sets of possibilities to which causal, enabling, and prevention relations refer. They then selected an appropriate sentence from a set of assertions about the relations between an omission of a gate's action (i.e., not opening or not closing) and whether or not the ball "scored"- that is, reached the goal. The theory predicted that reasoners should select sentences that would accord with the appropriate relations.

\section{Method}

Participants A total of 31 participants (10 female, 21 male; mean age $=34.0$ years) volunteered through the Amazon Mechanical Turk online platform. Twenty of the participants reported no formal logic or advanced mathematical training, and the remainder reported introductory to advanced training. All participants were native English speakers.

Procedure Participants completed three practice problems and three experimental problems. Each problem consisted of viewing a set of animations that corresponded to different outcomes of a ball approaching a goal by entering a forked tube (akin to a game of miniature golf). Each animation depicted four key entities: a red ball, a green goal, a blue gate, and a tunnel that forked at its terminus. In the practice problems, after viewing the animations, participants judged whether the ball never, sometimes, or always entered the goal and scored. In the experimental problems, after viewing the animations, participants judged whether a gate's failure to open or its failure to close caused, enabled, or prevented the ball from scoring. They indicated their responses by selecting one of three sentences, which differed only in the causal verb

Table 2 Screenshots of the different animations for each of the three sorts of causal relationship tested in Experiment 4, along with the corresponding sentences that participants evaluated in the study (bolded responses are those predicted by the model theory)

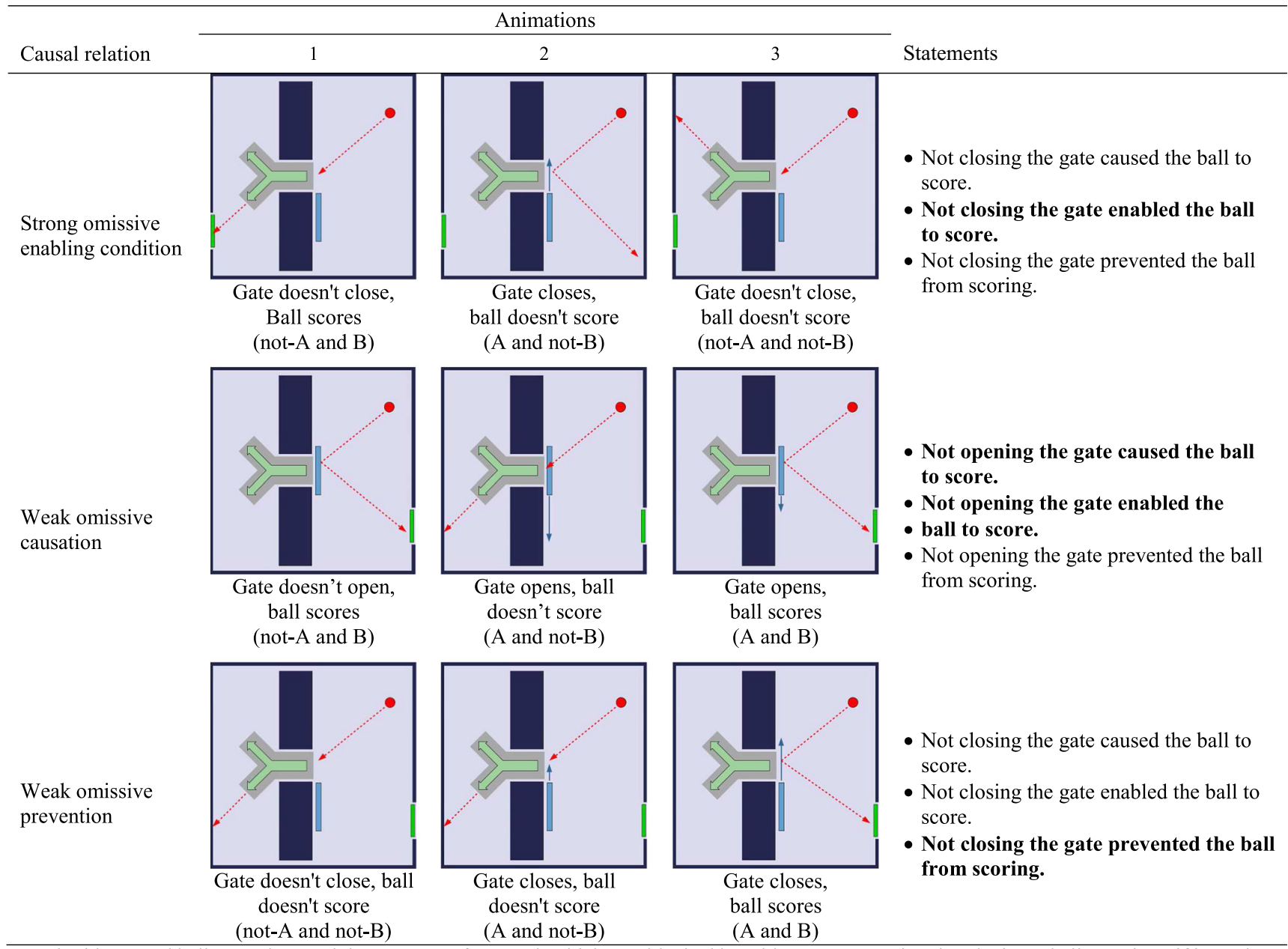

In each video, a red ball moved toward the entrance of a tunnel, which was blocked by a blue gate. An animation depicts a ball "scoring" if it reaches a green goal at either the left or the right of the animation. The screenshots are annotated as follows: A red dotted arrow represents the trajectory of the ball during the animation; the blue arrow represents the trajectory of the gate during the animation; and the absence of a blue arrow on the gate represents the scenario in which the gate does not move 
linking the two clauses (i.e., "caused," "enabled," and "prevented"). All of the information and the animations were presented simultaneously. They were required to view each animation at least once and to select one response before continuing to the next problem. No time limit was imposed for each trial, and there was no upper limit on the number of times that participants could rewatch each animation.

Materials and design Each of the three experimental problems consisted of three animations that depicted a ball moving from the right side of the screen toward the entrance of the tunnel, which was always oriented such that the fork was on the left side of the screen. The animations corresponded to one of three causal relations: weak omissive causation, strong omissive enabling conditions, and weak omissive prevention. Each of the relations referred to three contingencies, so the three animations that participants evaluated corresponded to a different contingency to which the relation referred according to the model theory. Table 2 provides a schematic of the different animations used in each condition.

Participants acted as their own controls and were presented with all three experimental problems. The order of the problems was rotated across participants following a Williams square design (Williams, 1949), which controlled for carryover effects between trials. On each trial, the three animations appeared in a row at the top of the screen, and the order in which they were visually presented (i.e., leftmost, centered, and rightmost) was randomized. The order of the sentences presented to participants was also randomized.

\section{Results and discussion}

Figure 4 shows the proportions of selections of the three causal verbs as a function of the causal relation to which the animations on a given trial corresponded. Participants differed in their propensity to select assertions with "enabled," "caused," or "prevented" as the causal verb, depending on the set of animations that they viewed (Friedman nonparametric analyses of variance, $\left.\chi^{2} \mathrm{~s}>12.16, p s>.002\right)$. In particular, participants selected "caused" more often for problems depicting weak omissive causal relations than for those that did not ( $35 \%$ vs. $8 \%$, Wilcoxon test, $z=2.42, p=.02$, Cliff's $\delta=$ $.27)$; they selected "enabled" more often for problems whose animations depicted strong enabling conditions than for those that did not $(87 \%$ vs. $32 \%$, Wilcoxon test, $z=4.44, p<.0001$, Cliff's $\delta=.76$ ); and they selected "prevented" more often for problems depicting weak omissive preventions than for those that did not (74\% vs. $11 \%$, Wilcoxon test, $z=4.32, p=.0002$, Cliff's $\delta=0.68$ ). Each of these patterns validated the third prediction of the model theory.

An unexpected pattern of results was that reasoners chose "enabled" more often than they chose "caused" for omissive causation animations (see the gray bars in Fig. 4). The model

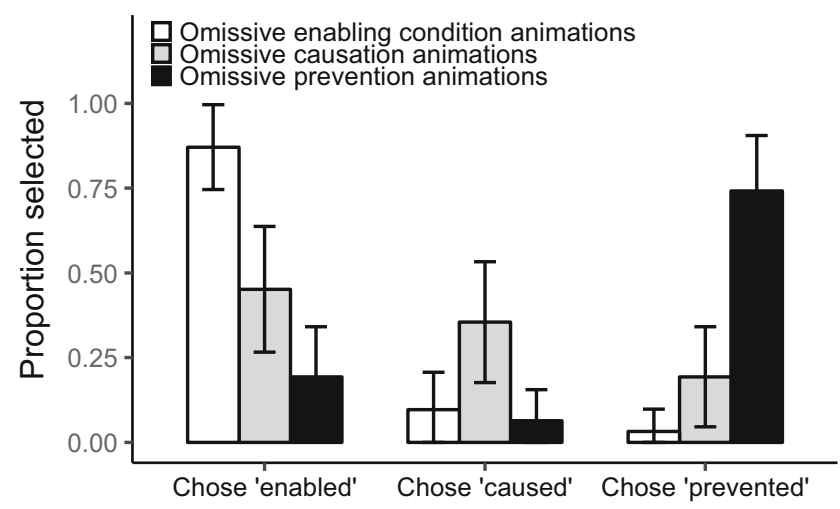

Fig. 4 Proportions of responses selected for the three causal verbs in Experiment 4 as a function of the causal relation depicted in the animations (strong omissive enabling vs. weak omissive causation vs. weak prevention). Error bars show $95 \%$ confidence intervals

theory explains the pattern, however: Animations that depict weak omissive causation relations are also consistent with weak omissive enabling conditions, because weak enabling conditions are consistent with all four contingencies (see Table 1). Hence, the theory allows that participants may select either "caused" or "enabled" for such problems.

Experiment 4 extended the analyses of the previous studies to a visual domain in which participants viewed animations corresponding to different possibilities. It provided additional evidence that, in line with the second prediction of the model theory, reasoners distinguish omissive causal relations from omissive enabling conditions. It also validated the theory's third prediction about omissive prevention conditions. Finally, it showed that reasoners do not conflate enabling conditions with causal relations when the relevant contingencies are consistent with strong omissive enabling conditions - that is, when the contingencies make salient those possibilities that are diagnostic of a particular omissive relation.

\section{General discussion}

Many causes in daily life are omissive: The failure to stop at a traffic light can cause an accident. But few psychological accounts of causal reasoning explain how omissions are represented. We have described a new model-based theory that interprets omissive causation (e.g., "The absence of breathing causes death") as causation in which the antecedent possibility is negated (e.g., "not breathing"). The theory posits that individuals reason on the basis of discrete representations, and it distinguishes three sorts of omissive relations: omissive causation, omissive enabling conditions, and omissive prevention. It also separates reasoners' competence with omissive causes from their performance, in that it predicts that reasoners tend to represent one privileged model, the mental model, from the distinct models of possibilities referred to by the different omissive relations. 
Four experiments established that reasoners distinguish cases of omissive causation from omissive enabling and omissive prevention on the basis of their fully explicit models. In Experiments 1-3 we presented participants with verbal premises asserting causal relations-for example, "Not printing a particular political opinion will enable a certain newspaper's popularity to decrease." Reasoners then selected the possibilities that corresponded to the assertion (Exps. 1 and 2) or else they evaluated possibilities on the basis of whether they were consistent with the other premises (Exp. 3). Experiment 3 replicated the results of the first two experiments and extended them to a novel task. All three experiments revealed a divergence between causes and enabling conditions, but the reasoners in Experiment 3 selected the $A$ and $B$ possibility as being compatible with both omissive causation and omissive enabling conditions. One deflationary account for this behavior is that enabling conditions are more difficult to understand, so they add noise to reasoners' evaluations. Another account consistent with the model theory is that participants may have interpreted "enables" as referring to weak, not strong, enabling conditions (see Table 1). To test between those alternative accounts, in Experiment 4 we presented participants with strong enabling conditions. In the experiment, reasoners viewed animations that corresponded to weak causal relations, weak prevention relations, and strong enabling conditions, and they chose assertions that best characterized the relations. They had little difficulty in accurately identifying enabling conditions or preventions from perceptual input, and, in line with the model theory, they conflated causes and enabling conditions, such that they selected both "caused" and "enabled" as the appropriate verbs to characterize weak causal relations. In sum, the results of all three experiments corroborated the predictions of the theory.

Can alternative theories of omissive causation account for these data? Wolff and his colleagues were among the first to propose a psychological account of omissive causation (Wolff et al., 2010); their theory is inspired by process theories in philosophy insofar as it characterizes causation as a "force" that can be transferred and formalized using vector calculus (Wolff, 2007). The force theory posits that individuals mentally simulate interacting causal relations, such as enabling conditions and preventions, as different arrangements of force vectors. The theory's account of omissions is that they are embedded within double preventions (Wolff et al. 2010, p. 193). That is, the force theory interprets causation by omission, as in "the absence of $\mathrm{A}$ causes not-B," as: "X prevents A and A prevents B." Similar accounts of omissive causation by double prevention exist in philosophy (Collins, 2000; Dowe, 2001; Hall, $2000,2004)$, but the force theory is unique in its mathematical account of how to compose two prevention vectors to yield an omissive causation relation.
The present results challenge the force theory in two ways. First, the theory assumes that omissive causation is a result of "the removal or nonrealization of an anticipated force" (see above). The force theory assumes an anticipated force, $X$, in the double prevention: "X prevents A and A prevents B." That anticipated force might be easy to identify in physical examples, but it is much more difficult to instantiate appropriate force vectors in the social and economic examples used in our materials or in the medical malpractice example given in the introduction. A second challenge is that the force theory's mechanisms for composing double preventions yield a curious result: Omissive causes can be construed as omissive enabling conditions (Wolff et al., 2010, p. 198). The authors presented evidence that corroborated the conflation, but the experiments we have described show that reasoners systematically distinguish omissive causes and omissive enabling conditions.

A more recent psychological proposal treats omissive causation as a conditional probability (Stephan, Willemsen, \& Gerstenberg, 2017). The authors interpreted "the absence of A causes B" as the conditional probability of $A$ given that $B$ doesn't hold, symbolized as: $\mathrm{P}(A \mid \neg B)$. They argued that reasoners should base causal judgments on mental simulations of counterfactuals - that is, by making probability judgments of how an outcome would have changed had the causal event (or omission) been replaced by another event. One limitation of the proposal is that conditional probabilities cannot distinguish between an omissive cause (e.g., "The failure to run a test caused suffering") and a counterfactual (e.g., "Had the doctor failed to run a test, the woman would have suffered"). A conditional probability would treat both as: $\mathrm{P}$ (suffering $\mid \neg$ test). Another limitation is that counterfactuals, by definition, only concern causal relations that occur in the past. Omissive causations can occur in the past, present, or future; for instance, it is sensible to say that "Not paying this month's credit card bill on time will cause financial problems." No counterfactual is relevant in that scenario, since the relevant fact of the matter-whether the bill was paid on time or not-is unknown at the time of its utterance.

The data we have reported challenge the idea that reasoners consider counterfactuals or multiple possibilities by default when thinking about causal relations: If reasoners had represented two contrasting scenarios at the outset, then they should not have privileged the mental model as they did in Experiments 1-3. Indeed, they should have asserted the two separate possibilities analogously. The results instead suggest that reasoners prefer to represent one possibility over all others. Possibilities beyond that preferred mental model must be fleshed out. Since doing so demands cognitive resources, additional possibilities should be asserted less frequently and should succeed possibilities corresponding to mental models. Future experiments will assess this proposal directly. 


\section{Conclusion}

Perhaps the present results triple the dilemma for metaphysicians: In addition to explaining what an omission is and how it might cause an outcome, they must also theorize about how omissions enable and prevent outcomes. The psychological theory we outline, however, explains how humans represent omissive causes. People build mental simulations of discrete alternative possibilities when assessing omissions - an idea anticipated, but not elaborated on, by other philosophers (see, e.g., Bernstein, 2014; Geurts, 2005). The model theory explains why the different relations should be distinct: They refer to different sets of possibilities. And it explains why people privilege some possibilities over others: Many reasoners consider only one possibility - the mental model-when comprehending omissive causal relations, but those who consider additional possibilities are less likely to err.
Author note We are grateful to Kalyan Gupta, Kevin Zish, and the Knexus Research Corporation for their help in conducting the experiments, and also to Brian McClimens and Tucker Maney for their help developing the animations and the experimental code. We also thank Monica Bucciarelli, Ruth Byrne, Felipe de Brigard, Todd Gureckis, Paul Henne, Tony Harrison, Laura Hiatt, Zach Horne, Phil Johnson-Laird, Joanna Korman, Robert Mackiewicz, Mike Oaksford, Greg Murphy, L. A. Paul, Bob Rehder, and Greg Trafton for their advice and comments. This work was supported by a National Research Council Research Associateship awarded to G.B. and by a grant from the Naval Research Laboratory awarded to S.K. and P.B. Portions of the research were presented at the Annual Conference of the Cognitive Science Society in 2015 and 2017, at the New York University ConCats group in 2016, and at the Imagination and Modal Cognition Laboratory at Duke University in 2016 and 2018.

\section{Appendix}

Table 3 The materials used in Experiments 2 and 3

\begin{tabular}{|c|c|c|c|c|}
\hline \multirow[t]{2}{*}{ Domain } & \multirow[t]{2}{*}{ First Premise } & \multirow[t]{2}{*}{ Second Premise } & \multicolumn{2}{|c|}{ Experiment } \\
\hline & & & 2 & 3 \\
\hline Biological/Physiological & Michael was bitten by a deadly snake. & Not taking a particular antidote will ___ Michael's death. & & $\mathrm{X}$ \\
\hline Biological/Physiological & $\begin{array}{l}\text { Andrew participates in aerobic exercise classes } \\
\text { regularly. }\end{array}$ & $\begin{array}{l}\text { The lack of a particular vitamin supplement will __ Andrew's } \\
\text { blood pressure to rise. }\end{array}$ & $\mathrm{X}$ & $\mathrm{X}$ \\
\hline Biological/Physiological. & Joseph has eaten a meal for dinner. & $\begin{array}{l}\text { The absence of a particular ingredient will __ Joseph to get } \\
\text { indigestion. }\end{array}$ & & $\mathrm{X}$ \\
\hline Biological/Physiological & Thomas is following a new diet. & $\begin{array}{l}\text { Not eating a particular food group will __ Thomas to lose } \\
\text { weight. }\end{array}$ & $\mathrm{X}$ & $\mathrm{X}$ \\
\hline Biological/Physiological & David has had hip replacement surgery. & Not doing a particular physical activity will ___ David to heal. & $\mathrm{X}$ & \\
\hline Mechanical & A particular car engine requires maintenance. & The absence of a particular part will __ the engine to fail. & $\mathrm{X}$ & $\mathrm{X}$ \\
\hline Mechanical & A particular hydroelectric turbine converts energy. & $\begin{array}{l}\text { The lack of water pressure will __ energy production to } \\
\text { decrease. }\end{array}$ & $\mathrm{X}$ & $\mathrm{X}$ \\
\hline Mechanical & A particular tractor operates in harsh conditions. & $\begin{array}{l}\text { Not having regular oil changes will __ the tractor to } \\
\text { malfunction. }\end{array}$ & $\mathrm{X}$ & $\mathrm{X}$ \\
\hline Mechanical & A particular machine has a brake lever. & Not pulling the lever will ___ the machine to work efficiently. & $\mathrm{X}$ & \\
\hline Mechanical & A particular computer generates data. & $\begin{array}{l}\text { The lack of virus protection software will__ the computer } \\
\text { to perform slower. }\end{array}$ & & $\mathrm{X}$ \\
\hline Natural & A loaf of bread is baking in a particular oven. & Not including baking powder will ___ the dough to fall. & & $\mathrm{X}$ \\
\hline Natural & A particular substance is organic. & $\begin{array}{l}\text { The lack of a certain preservative will __ the substance } \\
\text { to decay. }\end{array}$ & $\mathrm{X}$ & $\mathrm{X}$ \\
\hline Natural & A forest is on fire. & The lack of wind will the fire to dissipate. & $\mathrm{X}$ & $\mathrm{X}$ \\
\hline Natural & $\begin{array}{l}\text { The atmospheric pressure has changed in a particular } \\
\text { region. }\end{array}$ & $\begin{array}{l}\text { The absence of high pressure on a particular cold night } \\
\text { will it to be cloudy. }\end{array}$ & $\mathrm{X}$ & $\mathrm{X}$ \\
\hline Social/Economical & A store sells specialty items for holidays. & $\begin{array}{l}\text { The lack of a particular holiday item will __ shoppers } \\
\text { to complain. }\end{array}$ & $\mathrm{X}$ & $\mathrm{X}$ \\
\hline Social/Economical & A particular country exports goods. & $\begin{array}{l}\text { The absence of a particular commodity will __ trades } \\
\text { with that country to decrease. }\end{array}$ & $\mathrm{X}$ & $\mathrm{X}$ \\
\hline Social/Economical & $\begin{array}{l}\text { Daniel is staying at a particular hotel that is renting } \\
\text { rooms at a discount. }\end{array}$ & Not raising rates will ___ Daniel to extend the stay. & $\mathrm{X}$ & $\mathrm{X}$ \\
\hline Social/Economical & $\begin{array}{l}\text { A particular buyer is interested in obtaining a } \\
\text { mortgage to purchase a home. }\end{array}$ & $\begin{array}{l}\text { The absence of a buyer's debt will__ the buyer to receive } \\
\text { a low interest rate. }\end{array}$ & $\mathrm{X}$ & $\mathrm{X}$ \\
\hline
\end{tabular}




\section{References}

Barr, D. J., Levy, R., Scheepers, C., \& Tily, H. J. (2013). Random effects structure for confirmatory hypothesis testing: Keep it maximal. Journal of Memory and Language, 68, 255-278. https://doi.org/ 10.1016/j.jml.2012.11.001

Bates, D., Kliegl, R., Vasishth, S., \& Baayen, H. (2015). Parsimonious mixed models. arXiv: 1506.04967

Bernstein, S. (2014). Omissions as possibilities. Philosophical Studies, $167,1-23$.

Bernstein, S. (2016). Omission impossible. Philosophical Studies, 173, 2575-2589.

Byrne, R. M. J. (2005). The rational imagination: How people create alternatives to reality. Cambridge, MA: MIT Press.

Cheng, P. W., \& Novick, L. R. (1991). Causes versus enabling conditions. Cognition, 40, 83-120.

Clarke, R., Shepherd, J., Stigall, J., Waller, R. R., \& Zarpentine, C. (2013). Causation, norms, and omissions: A study of causal judgments. Philosophical Psychology, 28, 279-293. https://doi.org/10. 1080/09515089.2013.815099

Collins, J. (2000). Preemptive prevention. Journal of Philosophy, 97, 223-234.

Dowe, P. (1999). Good connections: Causation and causal processes. In H. Sankey (Ed.), Causation and laws of nature (pp. 247-263). Dordrecht, The Netherlands: Kluwer.

Dowe, P. (2001). A counterfactual theory of prevention and "causation" by omission. Australasian Journal of Philosophy, 79, 216-226.

Einhorn, H. J., \& Hogarth, R. M. (1986). Judging probable cause. Psychological Bulletin, 99, 3-19. https://doi.org/10.1037/00332909.99.1.3

Ferrara, S. D. (2013). Causal value and causal link. In S. D. Ferrara, R. Boscolo-Berto, \& G. Viel (Eds.), Malpractice and medical liability: European state of the art and guidelines (pp. 93-107). Berlin, Germany: Springer.

Frosch, C. A., \& Johnson-Laird, P. N. (2011). Is everyday causation deterministic or probabilistic? Acta Psychologica, 137, 280-291.

Geurts, B. (2005). Entertaining alternatives: disjunctions as modals. Natural Language Semantics, 13, 383-410. https://doi.org/10. 1007/s11050-005-2052-7

Godfrey-Smith, P. (2009). Causal pluralism. In H. Beebee, C. Hitchcock, \& P. Menzies (Eds.), The Oxford handbook of causation (pp. 326337). Oxford, UK: Oxford University Press.

Goldvarg, E., \& Johnson-Laird, P. (2001). Naïve causality: A mental model theory of causal meaning and reasoning. Cognitive Science, 25, 565-610. https://doi.org/10.1207/s15516709cog2504_3

Goodwin, G. P., \& Johnson-Laird, P. N. (2005). Reasoning about relations. Psychological Review, 112, 468-493. https://doi.org/10.1037/ 0033-295X.112.2.468

Gureckis, T. M., Martin, J., McDonnell, J., Rich, A. S., Markant, D., Coenen, A., . . C Chan, P. (2016). psiTurk: An open-source framework for conducting replicable behavioral experiments online. Behavior Research Methods, 48, 829-842. https://doi.org/10.3758/ s13428-015-0642-8

Hall, N. (2000). Causation and the price of transitivity. Journal of Philosophy, 97, 198-222.

Hall, N. (2004). Two concepts of causation. In J. Collins, N. Hall, \& L. A. Paul (Eds.), Causation and counterfactuals. Cambridge, MA: MIT Press.

Hall, N. (2007). Structural equations and causation. Philosophical Studies, 132, 109-136.

Halpern, J. Y., \& Hitchcock, C. (2014). Graded causation and defaults. British Journal for the Philosophy of Science, 66, 413-457.
Halpern, J., \& Pearl, J. (2005). Causes and explanations: A structuralmodel approach - Part I: Causes. British Journal for the Philosophy of Science, 56, 843-887.

Hart, H. L. A., \& Honoré, T. (1985). Causation in the law (2nd ed.). Oxford, UK: Oxford University Press, Clarendon Press.

Henne, P., Pinillos, Á., \& De Brigard, F. (2017). Cause by omission and norm: Not watering plants. Australasian Journal of Philosophy, 95, 270-283. https://doi.org/10.1080/00048402.2016.1182567

Hilton, D. J., \& Erb, H.-P. (1996). Mental models and causal explanation: Judgements of probable cause and explanatory relevance. Thinking \& Reasoning, 2, 273-308.

Hunt, A. (2014). Hamilton jury awards $\$ 1.2 \mathrm{M}$ in malpractice suit. Cincinnati Enquirer. Retrieved from www.cincinnati.com/story/ news/courts/2014/09/11/medical-malpractice-lawsuit/15460567/

Johnson-Laird, P. N. (2006). How we reason. New York, NY: Oxford University Press.

Johnson-Laird, P. N., \& Byrne, R. M. J. (1991). Deduction. Hillsdale, NJ: Erlbaum.

Johnson-Laird, P. N., \& Byrne, R. M. J. (2002). Conditionals: A theory of meaning, pragmatics, and inference. Psychological Review, 109, 646-678. https://doi.org/10.1037/0033-295X.109.4.646

Johnson-Laird, P. N., \& Khemlani, S. (2017). Mental models and causation. In M. Waldmann (Ed.), Oxford handbook of causal reasoning (pp. $\mathrm{xxx}-\mathrm{xxx}$ ). Oxford, UK: Oxford University Press.

Johnson-Laird, P. N., Khemlani, S., \& Goodwin, G. P. (2015). Logic, probability, and human reasoning, Trends in Cognitive Sciences, 19, 201-214.

Kahneman, D., \& Miller, D. T. (1986). Norm theory: Comparing reality to its alternative. Psychological Review, 93, 75-88.

Khemlani, S., Barbey, A., \& Johnson-Laird, P. N. (2014). Causal reasoning with mental models. Frontiers in Human Neuroscience, 8, 849: 1-15. https://doi.org/10.3389/fnhum.2014.00849

Khemlani, S., Byrne, R. M. J., \& Johnson-Laird, P. N. (in press). Facts and possibilities: A model-based theory of sentential reasoning. Cognitive Science.

Khemlani, S., Orenes, I., \& Johnson-Laird, P. N. (2012). Negation: A theory of its meaning, representation, and use. Journal of Cognitive Psychology, 24, 541-559.

Lewis, D. (1973). Counterfactuals. Oxford, UK: Blackwell.

McGrath, S. (2005). Causation by omission: A dilemma. Philosophical Studies, 123, 125-148.

Menzies, P. (2004). Causal models, token causation, and processes. Philosophy of Science, 71, 820-832.

Menzies, P. (2007). Causation in context. In H. Price \& R. Corry (Eds.), Causation, physics, and the constitution of reality (pp. 191-223). Oxford, UK: Oxford University Press.

Mill, J. S. (1874). A system of logic, ratiocinative and inductive: Being a connected view of the principles of evidence and the methods of scientific evidence (8th ed.). New York, NY: Harper. (First edition published 1843)

Orenes, I., Beltrán, D., \& Santamaría, C. (2014). How negation is understood: Evidence from the visual world paradigm. Journal of Memory and Language, 74, 36-45.

Paolacci, G., Chandler, J., \& Ipeirotis, P. G. (2010). Running experiments on amazon mechanical turk. Judgment and Decision Making, 5, $411-419$.

Paul, L. A., \& Hall, N. (2013). Causation: A user's guide. New York, NY: Oxford University Press.

Peirce, C. S. (1958). Collected articles of Charles Sanders Peirce: Vol. 4. Exact logic, the simplest mathematics (C. Hartshorne \& P. Weiss, Eds.). Cambridge, MA: Harvard University Press, Belknap Press.

Salmon, W. (1984). Scientific explanation and the causal structure of the world. Princeton, NJ: Princeton University Press.

Skyrms, B. (1980). Causal necessity. New Haven, CT: Yale University Press. 
Sloman, S. A., Barbey, A. K., \& Hotaling, J. (2009). A causal model theory of the meaning of cause, enable, and prevent." Cognitive Science, 33, 21-50.

Sloman, S. A., \& Lagnado D. (2015). Causality in thought. Annual Review of Psychology, 66, 223-247.

Stephan, S., Willemsen, P., \& Gerstenberg, T. (2017). Marbles in inaction: Counterfactual simulation and causation by omission. In G. Gunzelmann, A. Howes, T. Tenbrink, \& E. Davelaar (Eds.), Proceedings of the 39th Annual Conference of the Cognitive Science Society (pp. 1132-1137). Austin, TX: Cognitive Science Society.
Strevens, M. (2013). Causality reunified. Erkenntnis, 78, 299-320.

Williams, E. J. (1949). Experimental designs balanced for the estimation of residual effects of treatments. Australian Journal of Scientific Research, Series A, 2, 149-168.

Wolff, P. (2007). Representing causation. Journal of Experimental Psychology: General, 136, 82-111.

Wolff, P., Barbey, A., \& Hausknecht, A. (2010). For want of a nail: How absences cause events. Journal of Experimental Psychology: General, 139, 191-221. https://doi.org/10.1037/a0018129 